\title{
Design principles for hydrogen evolution reaction catalyst materials
}

\author{
Dusan Strmcnik*, Pietro Papa Lopes, Bostjan Genorio, Vojislav R. Stamenkovic and Nenad M. \\ Markovic
}

Materials Science Division, Argonne National Laboratory, Argonne, IL 60439

*corresponding author: strmcnik@anl.gov

\begin{abstract}
Design and synthesis of active, stable and cost-effective materials for efficient hydrogen production (hydrogen evolution reaction, HER) is of paramount importance for the successful deployment of hydrogen-based alternative energy technologies. The HER, seemingly one of the simplest electrochemical reactions, has served for decades to bridge the gap between fundamental electrocatalysis and practical catalyst design. However, there are still many open questions that need to be answered before it would be possible to claim that design principles of catalyst materials are fully developed for the efficient hydrogen production. In this review, by summarizing key results for the HER on well-characterized electrochemical interfaces in acidic and alkaline media, we have broadened our understanding of the HER in the whole range of $\mathrm{pH}$ by considering three main parameters: the nature of the proton donor $\left(\mathrm{H}_{3} \mathrm{O}^{+}\right.$in acid and $\mathrm{H}_{2} \mathrm{O}$ in alkaline), the energy of adsorption of $\mathrm{H}_{\mathrm{ad}}$ and $\mathrm{OH}_{\mathrm{ad}}$, and the presence of spectator species. Simply by considering these three parameters we show that great deal has already been learned and new trends are beginning to emerge, giving some predictive ability with respect to the nature of electrochemical interface and electrocatalytic activity of the HER.
\end{abstract}

\section{Introduction}

For more than 70 years, there has been a substantial academic interest and technological development effort directed towards fundamental understanding of the hydrogen evolution reaction (HER) and the development of materials for efficient hydrogen production in acid $\left(2 \mathrm{H}^{+}+2 \mathrm{e}^{-} \leftrightarrow \mathrm{H}_{2}\right)$ 
and alkaline $\left(2 \mathrm{H}_{2} \mathrm{O}+2 \mathrm{e}^{-} \leftrightarrow \mathrm{H}_{2}+2 \mathrm{OH}^{-}\right)$environments [1-8]. However, three of the fundamental catalytic limitations that have plagued electrochemical production of hydrogen for decades still remain: (i) the efficiency in real-world industrial operation is considerably below the thermodynamic limits for the water splitting reaction $(1.223 \mathrm{~V})$; (ii) the lifetime of electrode materials is too short; and (iii) there is a lack of a cost-effective replacement for noble metals. Currently, various combinations of metals (Pt, Pd, Ir, Ru, Ni), metal alloys (Ni-Co, Ni-Mo, Ni$\mathrm{Mn})$, substrates with $3 \mathrm{~d}$ transition metal $(3 \mathrm{~d}-\mathrm{TM}=\mathrm{Ni}, \mathrm{Co}, \mathrm{Fe}, \mathrm{Mn})$ hydroxides $\left(3 \mathrm{~d}-\mathrm{TM}(\mathrm{OH})_{2}\right)$, 3d-TM phosphides $(\mathrm{CoP}, \mathrm{NiP}), 3 \mathrm{~d}-\mathrm{TM}$ carbides $\left(\mathrm{WC}_{\mathrm{x}}, \mathrm{MoC}_{\mathrm{x}}\right)$ and transition metal sulfides $\left(\mathrm{TMS}_{\mathrm{x}}=\mathrm{MoS}_{2}, \mathrm{CoS}_{2}, \mathrm{FeS}_{2}, \mathrm{Mo}_{3} \mathrm{~S}_{13}\right.$ ) [5,9-39] are used to catalyze the conversion of $\mathrm{H}_{3} \mathrm{O}^{+}$(acid) and $\mathrm{H}_{2} \mathrm{O}$ (alkaline) to $\mathrm{H}_{2}$. Not surprisingly, the exchange current density, defined as the rate at which reaction proceeds at the equilibrium (zero net current) potential, on these materials varies by $5-6$ orders of magnitude, with the highest rates observed on electrode materials with an optimal interaction of hydrogen intermediates with the catalyst surface [3,40-44]. Surprisingly, however, it has been found that activities are higher in acid than in alkaline electrolytes $[16,17,45-48]$; suggesting that there are both qualitative and quantitative differences between the HER in alkaline and acidic media, a fact that has been recently readdressed in the electrochemical community. Along with intrinsic curiosity, the motivation to explore and eventually understand the puzzling role of $\mathrm{pH}$ comes from the stability issues that plague most non-precious metal catalysts in acid solutions. Therefore, moving to neutral or alkaline environments seems to be essential for the development of non-PGM HER catalysts. However, in order to tailor new materials for HER we have to understand the governing principles, descriptors and trends in all $\mathrm{pH}$ conditions, and only then explore different combinations of several distinct atoms serving as the active sites (science-based design), which can be further improved by utilizing distinct morphologies as encountered in nanoparticles, nanoporous structures, or thin-films (engineering-based design).

Certainly, a vast electrochemical literature can be found addressing distinct aspects of the HER mechanism. The most used descriptor for the reaction is the metal- $\mathrm{H}_{\mathrm{ad}}$ bond energy $[3,40-$ 44], which still does not sufficiently explain the experimental lower activity in alkaline solutions. Based on our recent studies of the HER, we identify that in addition to $\mathrm{M}-\mathrm{H}_{\mathrm{ad}}$ energetics ( $\mathrm{pH}$ independent) two other descriptor are required to understand hydrogen electrocatalysis, at least from experimental point of view: i) the nature of the proton source, and ii) presence of surface 
spectators. Although one can easily find the literature that supports the $\mathrm{M}-\mathrm{H}_{\mathrm{ad}}$ binding energy as a sole descriptor, here we will focus on demonstrating the importance of the above three descriptors through our own findings as well as with selected literature. Note that this review is not intended to be exhaustive, e.g., issues with more applied aspects of HER, such as investigations on high surface area materials with ill-defined active sites, have also largely been omitted here in preference of systems that are well defined with respect to surface geometry and nature of active sites. Furthermore, many important computational based electrocatalytic trends [7,43,44,49-56] (thermodynamics-based volcano curves) have not been reviewed in any detail.

\section{HER on metal single crystal and polycrystalline surfaces:}

The role of $\mathbf{p H}$ in the HER. The HER in alkaline solutions is usually assumed to proceed by an initial discharge of water and the formation of hydrogen intermediates $\left(\mathrm{H}_{\mathrm{ad}}\right.$, historically termed "overpotential hydrogen" [41]) in the so-called Volmer step $\left(\mathrm{H}_{2} \mathrm{O}+\mathrm{e}^{-}+\mathrm{M} \leftrightarrows\right.$ $\left.\mathrm{M}-\mathrm{H}_{\mathrm{ad}}+\mathrm{OH}^{-}\right)$; followed by either the electrochemical Heyrovsky step $\left(\mathrm{H}_{2} \mathrm{O}+\mathrm{M}-\mathrm{H}_{\mathrm{ad}}+\mathrm{e}^{-} \leftrightarrows \mathrm{M}+\right.$ $\left.\mathrm{H}_{2}+\mathrm{OH}^{-}\right)$or the chemical Tafel recombination step $\left(2 \mathrm{H}_{\mathrm{ad}} \leftrightarrows \mathrm{H}_{2}\right)$. The reaction pathway in acidic solutions is similar except that $\mathrm{H}_{a d}$ is formed by discharge of the hydronium ion $\left(\mathrm{H}_{3} \mathrm{O}^{+}+\mathrm{M}+\mathrm{e}^{-}\right.$ $\leftrightarrows \mathrm{H}_{\mathrm{ad}}+\mathrm{H}_{2} \mathrm{O}$ ). Thus far, the guiding principle for HER catalysts development in acid media involves the well-known concept of the volcano plots $[3,40-42,44]$; expressing the relationship between the rate of the HER and some type of metal-hydrogen bonding [40,41,44,53] (adsorption or metal-hydride bond energy), as well as the metal work functions [3,57]. This volcano relationship, observed both from experimental and computational studies [42,44,53], predicts that metals that adsorb hydrogen neither too strongly nor too weakly (the Pt-group metals) will display highest activity, namely, will occupy the top of volcano. Therefore, consecutive research efforts have mainly been focused on establishing how kinetic rates depend on the hydrogen-metal energetics.

Although the volcano trends have been demonstrated for the HER in both acidic as well as in alkaline media, they do not explain why most metal catalysts in alkaline medium display 2-3 orders of magnitude lower activity than in acid solutions. As summarized in Figure 1a-c, the HER studied on $\mathrm{Au}(111), \operatorname{Pt}(111)$, and polycrystalline Ir (Ir-poly) in solutions with varying $\mathrm{pH}$ values, from acidic $(\mathrm{pH}=1-4)$, to neutral $(\mathrm{pH}=4-11)$, and to alkaline $(\mathrm{pH}=11-13)$, also demonstrate this drastic decrease in activity [48]. Not surprising, the current-potential curves for 
$\mathrm{Au}(111)$ in acid ( $\mathrm{pH} 1)$ are shifted towards higher overpotentials ( 0.4-0.8 V) relative to $\mathrm{Pt}(111)$ and Ir-poly, still in agreement with the classical volcano trends. However, increasing the $\mathrm{pH}$ value up to $\mathrm{pH}=4$ changes the typical HER polarization profile, showing a pure diffusion limiting currents at higher overpotentials. We note that although the current density is the same for all three metals shown, the electrode potential range is characteristic for each of the surfaces [48]. Similar behavior has been found by other groups [58,59], implying that under these experimental conditions the HER is controlled by the mass transport of reactive hydronium species (denoted hereafter as the "proton branch", $\mathrm{H}_{3} \mathrm{O}^{+}$) rather than the charge transfer reaction. Finally, the polarization curves for each metal becomes $\mathrm{pH}$-independent above $\mathrm{pH}=5$ and potentials negative of $-1.5 \mathrm{~V}$ for $\mathrm{Au}(111),-0.9 \mathrm{~V}$ for $\mathrm{Pt}(111)$ and $-0.7 \mathrm{~V}$ for Ir-poly, indicating that in such conditions the HER currents are mainly controlled by the $\mathrm{pH}$-independent transformation of $\mathrm{H}_{2} \mathrm{O}$ to $\mathrm{H}_{2}$, i.e., the "water branch". Overall then, Strmcnik et al. [48], concluded that one fundamental difference between the HER in acidic and alkaline media is that in alkaline solutions the kinetics is limited by a sluggish water dissociation process, as water is the sole proton donor in this media. We note that, from several literature sources one can find that hydronium and hydroxide recombination is a fast reaction, in the order of $10^{11} \mathrm{~L} \mathrm{~mol}^{-1} \mathrm{~s}^{-1}$ [1,60-62]. Taking into account the water dissociation equilibrium constant $\left(\mathrm{K}_{\mathrm{w}}\right)$ of $10^{-14}$, it readily follows that the kinetic rate for $\mathrm{H}_{2} \mathrm{O}$ dissociation is in the order of $10^{-3} \mathrm{~mol} \mathrm{~L}^{-1} \mathrm{~s}^{-1}$, e.g., a typical slow kinetic rate for a reaction [62]. Because the role of water dissociation as the rate determining step is not accepted by the entire electrochemical community, with other researchers proposing different " $\mathrm{pH}$-models" [16,46,63], the interested reader is referred to the original references for details. We do, however, strongly criticize all studies that address fundamental issues in electrocatalysis by employing experiments on poorly defined high surface area nanoparticulate catalysts and supporting them with calculations on ideal model surfaces.

Structure-function relationships. A particular insightful, although rarely explored by other groups, means of probing the $\mathrm{pH}$ effects on the HER involves assessing the role of surface geometry on the kinetic rates. Importantly, while only a small difference in activity between Pt low-index single crystal surfaces has been found in acid environments, a substantial difference in activity is found in alkaline solutions [64-66] (Figure 2a). In order to understand such structurefunction relationships it is of interest to compare the surface morphology of $\mathrm{Pt}(\mathrm{hkl})$ with kinetic rates at a constant overpotential. For example, while an STM (scanning tunneling microscopy) 
image of the as-prepared $\mathrm{Pt}(111)$ electrode reveals that the surface is composed of a flat terrace which is covered by few steps and Pt ad-islands with monatomic height (Figure 2b), ad-islands with square shapes and monoatomic height are clearly evident on the as-prepared $\operatorname{Pt}(100)$ electrode (Figure 2c). The presence of such islands on $\operatorname{Pt}(100)$ is due to "lifting" of a (100)-hex phase and the formation of a (100)-(1x1) surface with "well-ordered" defects [47]. In the case of the $\operatorname{Pt}(110)$ the STM image (Figure 2d) reveals that even on a 100x100 nm scale, the surface is far from ideal. Importantly, the as-prepared surface morphology of these single-crystals remains unchanged after the HER measurement confirming that the reaction takes place on well-defined surfaces. As summarized in Figure 2a, the degree of activity, increasing in the order $(110)>(100)>(111)$, is proportional to the density of surface defects which, in line with UHV studies [65,67-71], has been proposed to be the active sites for the water dissociation step [7275].

Very recently, in order to develop more complete structure-function relationships for the HER, we compared the HER on $\operatorname{Pt}(111)$ and $\mathrm{Pt}(111)$ modified by electrochemically deposited Pt islands, referred as Pt-islands/Pt(111). In the STM image of Fig. 2e and 2f, the Pt ad-atoms can be clearly resolved as two-dimensional (2D) features with diameters of $\sim 1$ to $3 \mathrm{~nm}$ and a height of 1 atomic layer (Fig. 2c). More importantly, Fig. 2g shows that in alkaline solution the Ptislands/Pt(111) surface is $\sim 5$ to 6 times more active for the HER than the corresponding pristine $\mathrm{Pt}(111)$ surface. Fig. $2 \mathrm{~g}$ also shows that, in acid solution, the HER on the Pt-islands/Pt(111) electrode is improved by only a factor of $\sim 1.5$. In turn, this strong $\mathrm{pH}$ effect confirms that the low-coordinated Pt atoms have a significant effect on the rate determining step (rds) of the HER in alkaline solutions. Because the major difference between the reaction pathways in alkaline and acid solutions is that in alkaline solutions, the hydrogen is discharged from water instead of hydronium ions $\left(\mathrm{H}_{3} \mathrm{O}^{+}\right)$[48], it has been proposed that the large promoting effect of low-coordinated Pt atoms in alkaline solution is due to more facile dissociative adsorption of water. The role of edge-step sites in accelerating dissociative adsorption of water on metal surfaces is well documented in ultra-high vacuum (UHV) environments [65,67-71]. We conclude, therefore, that for materials with near-optimal $\mathrm{M}-\mathrm{H}_{\mathrm{ad}}$ energetics (such as $\mathrm{Pt}$ ), surface reactivity for the HER can be further improved by tailoring the active sites for more efficient dissociative adsorption of water molecules. A number of such attempts have, indeed, confirmed 
that for an efficient production of hydrogen in alkaline electrolytes two types of active sites are required, as we discuss further below for metal-hydroxyl oxide systems.

\section{HER on surfaces modified with $3 \mathrm{~d}-\mathrm{TM}(\mathrm{OH})_{2}$}

\section{Trends in actvity and reaction mechanism of 3d-TM(OH $)_{2}$ hydroxyl deposited on}

$\operatorname{Pt}(111)$. In order to further probe the importance of activating the water to evolve hydrogen in alkaline electrolytes, Submaraman et al., modified Pt(111) surfaces by depositing 3dTM (TM = $\mathrm{Ni} \mathrm{Co}, \mathrm{Fe}, \mathrm{Mn}$ ) hydroxide clusters [76], as the 3d-transition metal oxides are known to catalyze water dissociation in UHV systems [71]. Overall, detailed examination of the nature and morphology of these 3d-TM hydroxides revealed that for all of them the metal center were in $2+$ oxidation state, without any signs of metal deposition, and that they form randomly distributed clusters across the (111) terraces (STM images shown in Fig 3a-3e), grown as 3D islands by a Volmer-Weber mechanism, with spheroid likes shapes ranging from 7 to $10 \mathrm{~nm}$ in diameter and $\sim 0.49-0.65 \mathrm{~nm}$ tall, constituting of two layers of electrically conductive material $[45,76]$. Thus, seldom achieving a complete monolayer over the $\operatorname{Pt}(111)$ substrate, this $3 \mathrm{~d}-\mathrm{TM}(\mathrm{OH})_{2}$ clusters are stable in the potential range of interest for HER.

Having established the nature and morphology of the clusters, we briefly summarize their role in the HER on $\operatorname{Pt}(111)$. Although there are fewer Pt sites available on the bare $\operatorname{Pt}(111)$ substrate in the presence of $\mathrm{Ni}(\mathrm{OH})_{2}$ clusters, the $\mathrm{Ni}(\mathrm{OH})_{2} / \mathrm{Pt}(111)$ electrode is $\sim 7$ times more active for the HER than the corresponding bare $\mathrm{Pt}(111)$ electrode in $0.1 \mathrm{M} \mathrm{KOH}$ (Fig. 3f). Clearly, then, $\mathrm{Ni}(\mathrm{OH})_{2}$ must play a promoting role in the dissociation of water and thereby enhances the rate of formation of $\mathrm{H}_{\mathrm{ad}}$ intermediates on the metal surface, as the base substrate activity for $\mathrm{H}_{\mathrm{ad}}$ recombination is not affected by the presence of these hydroxide clusters [45,76]. As schematically depicted in Fig. 3g, it was proposed that water adsorption requires concerted interaction of $\mathrm{O}$ atoms with $\mathrm{Ni}(\mathrm{OH})_{2}$ and $\mathrm{H}$ atoms with $\mathrm{Pt}$ at the boundary between $\mathrm{Ni}(\mathrm{OH})_{2}$ and $\mathrm{Pt}$ domains - i.e. a formation of an activated water complex at the catalysts surface. Water adsorption is then followed by water dissociation and hydrogen adsorption $\left(\mathrm{H}_{\mathrm{ad}}\right)$ on the nearby vacant $\mathrm{Pt}$ sites. Finally, two $\mathrm{H}_{\mathrm{ad}}$ atoms on the Pt surface recombine to form $\mathrm{H}_{2}\left(\mathrm{H}_{2}\right.$ desorption step) and $\mathrm{OH}^{-}$desorbs from the $\mathrm{Ni}(\mathrm{OH})_{2}$ domains followed by adsorption of another water molecule on the same site. To the best of our knowledge, this was the very first example that unambiguously demonstrated the importance of bi-functionality in which $\mathrm{Ni}(\mathrm{OH})_{2}$ serves to catalyze the Volmer step, while Pt is required to 
optimize the adsorption energy of $\mathrm{H}_{\mathrm{ad}}$. The presence of a bi-functional mode of catalysis for the HER reaction is also supported by the observed effects of surface coverage by $\mathrm{Ni}(\mathrm{OH})_{2}$ [45]; e.g., the HER activities were found to initially increase with the addition of $\mathrm{Ni}(\mathrm{OH})_{2}$ to the $\operatorname{Pt}(111)$ surface reaching a maximum for a coverage $\sim 40-45 \%$, beyond which the activity begins to decrease. The existence of a maximum in the coverage vs. activity relationship, further confirms the need for bi-functional catalysts for the HER in alkaline solution. The rate of the reaction is therefore governed by optimizing the density and the nature of the sites required for dissociation of water (hydroxides) and recombination of hydrogen (Pt).

Based on this observation it was proposed that it is possible to fix the descriptor related to the adsorption energetics of $\mathrm{Pt}-\mathrm{H}_{\mathrm{ad}}$, so that the overall reaction can be treated as a 'pseudo' mono-functional reaction: controlled by the descriptor related to $\mathrm{OH}_{\mathrm{ad}}---\mathrm{M}^{2+\delta}$ bond strength. An example from our laboratory of the catalytic trends for the HER on $\operatorname{Pt}(111)$ modified with 3dTM is shown in Figure 3. Details of the analysis are given in Subbaraman et. al. [76]. Clearly, a monotonic relationship exists between the HER activity and the $\mathrm{OH}_{\mathrm{ad}}{ }^{-}-\mathrm{M}^{2+\delta}$ energetics, with the most active catalysts being $\mathrm{Ni}(\mathrm{OH})_{2} / \mathrm{Pt}(111)$ and the least active $\mathrm{Mn}(\mathrm{OH})_{2} / \mathrm{Pt}(111)$. Based on the observed catalytic trends, it was proposed that a balance must be found between the transition state energies for water dissociation and the final state energies of adsorbed $\mathrm{OH}_{\mathrm{ad}}$ on $\mathrm{M}^{2+\delta} \mathrm{O}^{\delta}(\mathrm{OH})_{2-\delta}$ [71]. According to the standard Brønsted-Evans-Polanyi-type principles [56], this results in lower activation barriers for water dissociation, at the expense of increased poisoning effect due to less available sites for re-adsorption of water. The net result is that the turnover frequency substantially decreases (below bare Pt activity) for the Fe and Mn hydr(oxy)oxides on which $\mathrm{OH}_{\mathrm{ad}}$ is more strongly adsorbed. In essence, this suggests that the Fe and Mn behave purely as spectators, blocking the $\mathrm{Pt}$ active sites for transforming $\mathrm{H}_{2} \mathrm{O}$ to $\mathrm{H}_{2}$. The best combination among the $3 \mathrm{~d}$-elements considered thus far is found for the $\mathrm{Ni}(\mathrm{OH})_{2} / \mathrm{Pt}(111)$, which has the most favorable balance between facilitating water dissociation and preventing "poisoning" with $\mathrm{OH}_{\mathrm{ad}}$ (water dissociation product), together with the optimal Pt-Had energetics. The fact that the reactivity trends for the HER $(\mathrm{Ni}>\mathrm{Co}>\mathrm{Fe}>\mathrm{Mn})$, on surfaces with constant $\mathrm{Pt}-\mathrm{H}_{\mathrm{ad}}$ interaction, are identical to the trends in oxophilicity, established from the CO oxidation reaction and the OER, validates the use of $\mathrm{OH}_{\mathrm{ad}}---\mathrm{M}^{2+\delta}$ interaction strength as the descriptor below $0 \mathrm{~V}$, which is controlling the HER on the $\mathrm{M}^{2+\delta} \mathrm{O}^{\delta}(\mathrm{OH})_{2-\delta} / \mathrm{Pt}$ systems. 


\section{The common descriptors for HER:}

Although metal-hydrogen energetics can be used as a descriptor for obtaining the volcano plots for HER rate in acidic media, Schmickler et al. have recently stressed that these volcano plots lose their volcano shape once the points represented by oxide-covered metals such as Mo, $\mathrm{Ti}$ and $\mathrm{W}$ are removed from the plot [52]. Furthermore, as pointed out earlier in our manuscript, if the energy of $\mathrm{H}$ adsorption is the only descriptor for the rate of the HER in aqueous environments and it is determined solely by the nature of the metal and hydrogen, why do we observe systematically lower activities in alkaline environments? Based on our recent findings presented herein and supported with other literature data, we identify 3 major parameters that control the HER and combine them in a semi-empirical expression for reaction rate.

The proton donor: In essence, any hydrogen containing molecule can act as a proton donor. The equilibrium potential of evolving hydrogen from that proton donor will depend on the $\mathrm{pKa}$ value of the donor as well as its concentration. In aqueous environments, the activities of water $\mathrm{H}_{2} \mathrm{O}$ and hydronium $\mathrm{H}_{3} \mathrm{O}^{+}$and hydroxide $\mathrm{OH}^{-}$ions are in equilibrium determined by the water dissociation constant $\mathrm{K}_{\mathrm{w}}$.

$$
K_{w}=\frac{a_{H^{+}} a_{O H^{-}}}{a_{H_{2} O}^{2} \mathrm{O}}
$$

Therefore, for a reaction at an electrochemical equilibrium conditions, i.e. $\mathrm{i}=0$, it is thermodynamically irrelevant whether the proton for hydrogen evolution comes from hydronium ion or water. However, it can have a huge impact on the kinetics of the HER, as shown on the examples of $\mathrm{Au}$ (111) and Pt (111) in Figure 1, where polarization curves display an additional $400 \mathrm{mV}$ and $120 \mathrm{mV}$ overvoltage respectively, on top of the $720 \mathrm{mV}$ as expected when going from $\mathrm{pH} 1$ to $\mathrm{pH} 13$ on the SHE scale. As discussed by Delahay [1,77], the dissociation of water in alkaline solution is too slow to account for experimentally observed current densities by a mechanism involving dissociation of water and subsequent reduction of proton. Note that Tarasevich [78] and Petrii [57] also ascribe differences in the rate of HER/HOR to the origin of the proton $\left(\mathrm{H}_{2} \mathrm{O}\right.$ in alkaline, $\mathrm{H}_{3} \mathrm{O}^{+}$in acid). Only when the kinetics is very facile across the entire $\mathrm{pH}$ range, as is the case for Ir-poly, do we enter in quasi-equilibrium conditions at the electrode surface even at significant overpotentials, and therefore observe little or no difference between the two proton donors (Figure 1c). Note that in addition to $\mathrm{H}_{2} \mathrm{O}$ and $\mathrm{H}_{3} \mathrm{O}^{+}$we can have other 
proton donors present in the electrolyte, e.g. $\mathrm{HSO}_{4}{ }^{-}, \mathrm{HCO}_{3}{ }^{-}, \mathrm{H}_{2} \mathrm{PO}_{4}{ }^{-}$etc. which all can bring their own equilibria or kinetics into the resulting HER i-E characteristics, which will be the sum of the polarization curves of individual processes [59].

The energy of formation of activated complex from proton donor(s): Here, we broaden the concept of metal- $\mathrm{H}_{\mathrm{ad}}$ energetics to accommodate for the fact that hydrogen can be evolved from different proton donors. In the case of water as a proton donor, thoroughly addressed herein, our activated complex will also include metal- $\mathrm{OH}_{\mathrm{ad}}$ energetics in addition to metal- $\mathrm{H}_{\mathrm{ad}}$ energetics, therefore requiring catalyst's bi-functionality. As we demonstrate above, a good catalyst requires a balance between the catalyst- $\mathrm{H}_{\mathrm{ad}}$ and catalyst- $\mathrm{OH}_{\mathrm{ad}}$ interactions in such a way that it should be neither too noble for adsorption of hydrogen intermediates nor to oxophilic for adsorption of spectator hydroxyl ions. The requirement for the balance in energy of adsorption of hydrogen and hydroxyl species is of particular importance for the hydrogen oxidation reaction (HOR), also a rather slow process in alkaline solutions. In order to obtain high efficiency, the presence of $\mathrm{OH}_{\mathrm{ad}}$, serving as a promotor with an optimum surface coverage, is required to be present on the surface. For example, by alloying $\mathrm{Pt}$ with $\mathrm{Ru}$, it was possible to enhance the HOR by more than 5-fold compared to pure Pt [48].

The availability of active sites: In classical electrochemical kinetic equations one can find that availability of sites is expressed by the $\left(1-\theta_{i}\right)$ term, where $\theta_{i}$ represents the coverage by adsorbed intermediates. Specifically, for HER in acid solutions, $\theta_{i}$ would correspond to the coverage by adsorbed hydrogen $\mathrm{H}_{\mathrm{ad}}$. We believe, however, that it would be unreasonable to expect that the reaction intermediates are the only species contributing to the $\theta$ term as maybe the case in vacuum or heterogeneous catalysis. Rather, in the presence of $55 \mathrm{~mol} / \mathrm{L}$ of water and 0.1$1 \mathrm{~mol} / \mathrm{L}$ of supporting electrolyte, we can have an excess of additional species (these species can potentially include $\mathrm{OH}_{\mathrm{ad}}, \mathrm{H}_{\mathrm{ad}}, \mathrm{H}_{2} \mathrm{O}$, adsorbed anions and cations) present on the surface which are not involved in the reaction itself. We have emphasized the role of these "spectator" species many times in the last two decades [33,45,47,48,76,79-85]. The $\theta$ term must therefore also include the spectators $\left(\theta_{\mathrm{i}, \mathrm{s}}\right)$. Another important factor that we have discussed herein is the heterogeneity of the surface. More often than not, calculations on model systems do not include surface defects into account and the result can be huge discrepancy between theory and experiment. The $\left(1-\theta_{i, s}\right)$ term therefore addresses the availability of active sites, not the 
availability of total sites. For most of the electrochemical reactions, the actual active sites are still unknown which makes the analysis of the experimental data extremely difficult, but with the establishment of trends, it is possible to deduce with reasonable probability, what the active sites are.

Based on these three parameters, we can now write a general expression for the rate of HER in aqueous electrolytes away from the equilibrium potential:

$i=-2 F k^{0}\left(1-\theta_{i, S}\left(E, \Delta G_{1}^{0 \#}, \Delta G_{2}^{0 \#}, \Delta G_{S}^{0}\right)\right)\left[\left[H_{3} O^{+}\right]_{x=0} e^{\frac{-\Delta G_{1}^{0 \#}}{R T}} e^{\alpha_{1} \frac{F}{R T} E}+\left[H_{2} O\right]_{x=0} e^{\frac{-\Delta G_{2}^{0 \#}}{R T}} e^{\alpha_{2} \frac{F}{R T} E}\right]$

Where $\mathrm{i}$ is current density, $\mathrm{F}$ is faraday constant, $\mathrm{k}_{0}$ is a unit constant, $\mathrm{R}$ is standard gas constant, $\mathrm{T}$ is temperature, $\theta_{i, s}$ is the coverage by intermediates and spectator species, $\mathrm{E}$ is electrode potential, $E_{1}^{0}$ and $E_{2}^{0}$ are standard potentials for hydrogen reaction in acid and base respectively, $\Delta G_{s}^{0}$ is free energy of adsorbed spectators, $\left[\mathrm{H}_{3} \mathrm{O}^{+}\right]_{x=0}$ is proton concentration/activity at the electrode surface, $\left[\mathrm{H}_{2} \mathrm{O}\right]_{x=0}$ is water concentration/activity at the electrode surface, $\Delta G_{1}^{0 \#}$ is standard free energy of activated complex involving $\mathrm{H}_{3} \mathrm{O}^{+},-\Delta G_{2}^{0 \#}$ is standard free energy of activated complex involving $\mathrm{H}_{2} \mathrm{O}$ and $\alpha_{1}$ and $\alpha_{2}$ are the transfer coefficients of respective reactions. Note that the different colors used in equation 2 represent the 3 different descriptors: the proton donor (green), the free energy of adsorbed intermediates (red), and the availability of active sites (blue).

With equation 2 in mind, we now summarize some of our HER data and present in the form of bar graph in Fig. 4. The variations in activity for different materials are represented as the measured overpotential $(\eta$, defined as the difference between the measured electrode potential, E, and the equilibrium potential for the hydrogen reaction) at a constant current density for acid and alkaline environments. In addition, we also present data for $\mathrm{Ni}(\mathrm{OH})_{2}$ modified electrodes in alkaline media. Results are clustered in three groups; IB group metals, Pt-group metals and 3d-TM (for more details see ref. [85]). First, we point out that measured activities in alkaline are significantly lower than in acid solutions, consistent with differences in free energy of forming the activated complex from two different proton donors, i.e. water in alkaline solutions and hydronium ion in acid solutions. For Pt-group metals, all exhibit beneficial metal$\mathrm{H}_{\mathrm{ad}}$ energetics resulting in high activities for HER both on Pt and Ir in acid solution. In alkaline 
solution, however, the oxophilicity of Ir lowers the energetic barrier to activate water, hence higher activity for HER on Ir than Pt. Consequently, then, for the catalysts with comparable $\mathrm{M}-\mathrm{H}_{\mathrm{ad}}$ energetics, improving the water dissociation step can improve the alkaline HER activities. Despite favorable energetics, for more oxophilic metal such as $\mathrm{Ru}$ we observe lower activities in both acid and alkaline electrolytes due to the $\left(1-\theta_{i, s}\left(E, \Delta G_{1}^{0 \#}, \Delta G_{2}^{0 \#}, \Delta G_{s}^{0}\right)\right)$ term from equation 2. Strong adsorption of oxygenated species even in the HER potential region seems to be the predominant factor for HER on $\mathrm{Ru}$. As discussed by Schmickler et al.[52], this same term controls the HER electrochemistry on 3d-TM elements in aqueous environments. Furthermore, and contrary to Pt-group metals, for the IB group elements, the energetics of activated complex

from the proton donors $e^{\frac{-\Delta G_{1}^{0 \#}}{R T}}$ and $e^{\frac{-\Delta G_{2}^{0 \#}}{R T}}$ become the rate limiting factor. Note that the trends in activity are reverse in acid and alkaline solutions, i.e. $\mathrm{Au}>\mathrm{Ag}>\mathrm{Cu}$ for acid and $\mathrm{Cu}>\mathrm{Ag}>\mathrm{Au}$ in alkaline, signaling once more that the rate of reaction may be controlled by activation energy of water complex rather than adsorption energy of hydrogen, following the oxophilicity trend for these three metals. Lastly, all of the metal substrates were modified by $\mathrm{Ni}(\mathrm{OH})_{2}$ and HER trends in alkaline solutions reestablished. Modifying all the substrates by $\mathrm{Ni}(\mathrm{OH})_{2}$ (thereby establishing a constant rate of generation of "protons" from water dissociation), we aimed to transform $\mathrm{Ni}(\mathrm{OH})_{2} / \mathrm{M}$ bi-functionality to a "pseudo" mono-functional type of catalysts, in which the energetics for activating and splitting water would play a much lesser role. As shown in figure 4, the $\mathrm{Ni}(\mathrm{OH})_{2} / \mathrm{M}$ surfaces are, without exception, more active ( $\sim 3-5$ fold) than on corresponding bare substrates. In fact, we observe similar reactivity trends on $\mathrm{Ni}(\mathrm{OH})_{2} / \mathrm{M}$ catalysts in alkaline and in acidic solutions $(\mathrm{Au}>\mathrm{Cu}>\mathrm{Ag})$. Furthermore, there is no discernible difference in activity between $\mathrm{Ni}(\mathrm{OH})_{2} / \mathrm{Pt}$ and $\mathrm{Ni}(\mathrm{OH})_{2} / \mathrm{Ir}$, indicating that, as in acid solution, the HER is almost completely controlled by a similar hydrogen adsorption energy on these two surfaces. Therefore, it is reasonable to anticipate that $\mathrm{Ni}(\mathrm{OH})_{2}$ serves to enhance the water dissociation step (it does do so on IB-group metals and Pt-group metals), while the hydrogen recombination step takes place on the neighboring oxide/metal sites.

\section{Conclusion:}

In this mini review, we have presented some of our recent advancements in understanding of the HER in aqueous environments and supplemented them with important insights from other 
groups. We have shown that the HER in any aqueous system is controlled by three major parameters: i) the nature of the proton donor, ii) the energetics of the activated complex leading to the formation of $\mathrm{H}_{2}$ and iii) the availability of active sites for the reaction. We have demonstrated that in alkaline solutions the HER behaves inherently different from acid solutions because hydrogen is evolved from a different proton donor - water. Therefore, in order to form an activated water complex, a bifunctional catalyst that can stabilize both parts of water, i.e. $\mathrm{OH}$ and $\mathrm{H}$, will be the most advantageous. All catalysts are less active for HER in alkaline solutions than in acid solutions, however, all of them can be made significantly more active by modification with $\mathrm{Ni}(\mathrm{OH})_{2}$, which plays an important role in stabilizing water's $\mathrm{OH}$. Lastly, we show that the availability of active sites, i.e. the $\left(1-\theta_{i, s}\left(E, \Delta G_{1}^{0 \#}, \Delta G_{2}^{0 \#}, \Delta G_{s}^{0}\right)\right)$ term is the rate controlling factor for the transition metals which are known to be at least partially covered by oxides/hydroxides even at very negative potentials where HER takes place. With that in mind, we question the validity of the well-established volcano plots for HER in aqueous systems based solely on $\mathrm{M}-\mathrm{H}_{\mathrm{ad}}$ energetics.

Finally we point to a similar observation made by Tarasevich and Korchagin in their recent review [78]. Their analysis of the literature data revealed the following main factors controlling the hydrogen oxidation reaction (HOR): i) The energy of the adsorbed hydrogenmetal bond, ii) the proton source for different values of electrolyte $\mathrm{pH}\left(\mathrm{H}_{3} \mathrm{O}^{+}\right.$in acid, $\mathrm{H}_{2} \mathrm{O}$ in alkali) and iii) adsorption of different electrolyte ions. While they might give these factors different weight than we do, these are the same factors that control the HER. Nevertheless, it is interesting that after decades of research on electrochemistry of hydrogen reaction, many uncertainties still remain. While we hope that the new generation of in-situ experimental tools will be able to "see" the reactants, intermediates and products at the catalyst surface and address some of these open questions, we have no doubt that the hydrogen evolution reaction as well as its counterpart, the hydrogen oxidation reaction, are in a much better shape today than even a few years ago.

\section{Acknowledgments}


This work was supported by the Office of Science, Office of Basic Energy Sciences, Division of Materials Sciences, U.S. Department of Energy, under contract DE-AC02-06CH11357 (BESDMSE). 


\section{Figures:}
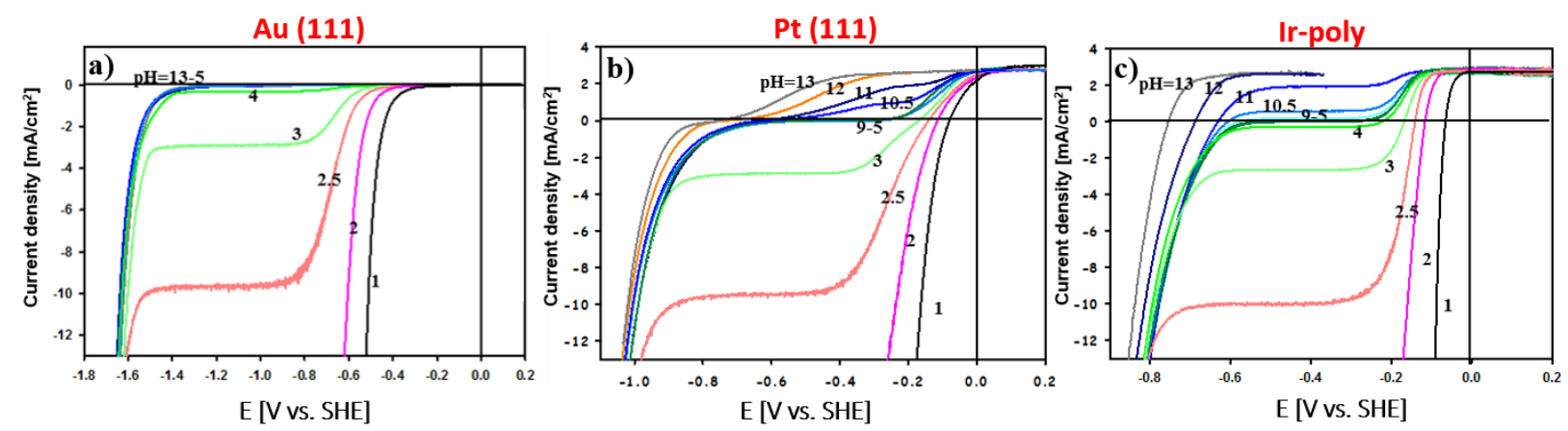

Figure 1: pH-dependent current-potential polarization curves at rotation rates of 1,600 rpm and sweep rate of $50 \mathrm{mV} / \mathrm{s}$ for $\mathrm{Au}(111)$ (a), $\operatorname{Pt}(111)$ (b) and Ir-poly (c). The presence of the proton branch and water branch for the HER can be clearly seen for all three electrodes. The potential is referenced versus the Standard Hydrogen Electrode: $\mathrm{Pt} / \mathrm{H}^{+}{ }_{\mathrm{aq}}(\mathrm{a}=1 \mathrm{~mol} / \mathrm{L}), \mathrm{H}_{2}(\mathrm{p}=1 \mathrm{~atm})$. Experiments were done in $0.1 \mathrm{M}$ $\mathrm{NaClO}_{4}$, purged with $\mathrm{H}_{2}$, $\mathrm{pH}$ was adjusted with addition of $\mathrm{NaOH}$ or $\mathrm{HClO}_{4}$. 

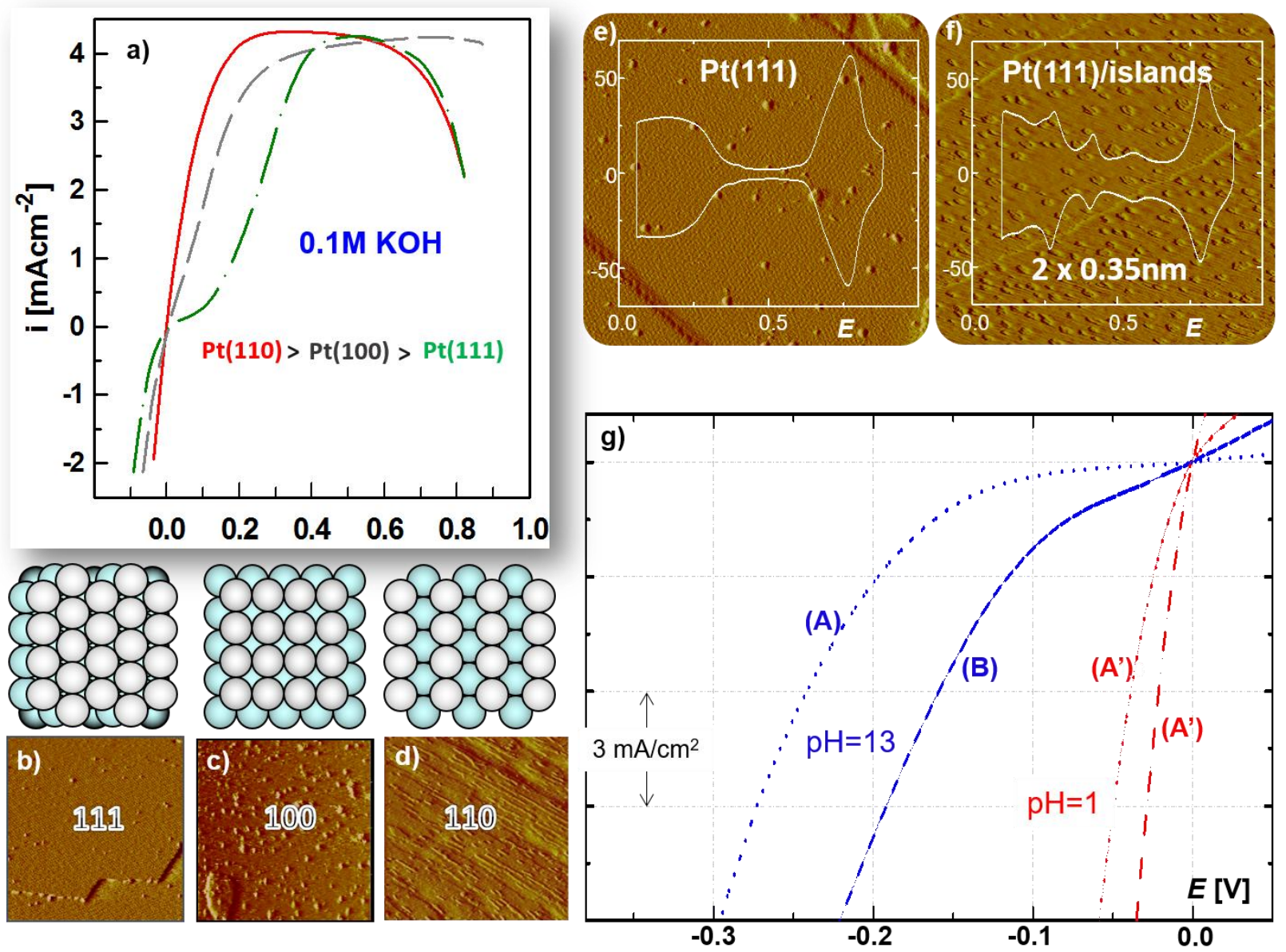

Figure 2: Clearly discernable structure dependent behavior of the HER/HOR on Pt (hkl) surfaces (a). STM images for $\mathrm{Pt}(111), \operatorname{Pt}(100)$ and $\mathrm{Pt}(110)$ with their corresponding structural models are presented in insets (b), (c) and (d). As prepared platinum (111) surface (e) exhibits large terraces with clearly visible steps and a small amount of adislands. Pt (111) surface purposefully decorated with significant amount of adislands (f) shows pronounced changes in voltammetry compared to as-prepared $\operatorname{Pt}(111)$, in addition to obvious morphological changes observed with STM. The electrochemical responses of the two surfaces are summarized in panel (g) with the two blue curves representing the differences in alkaline and the two red curves in acid solution. The response of the as-prepared surface is marked with (A)/(A)' whereas the modified surface response is marked with (B)/(B)'. All STM images depict a 100x100 nm area. Polarization curves were measured at $50 \mathrm{mV} / \mathrm{s}, 1600 \mathrm{rpm}$. 

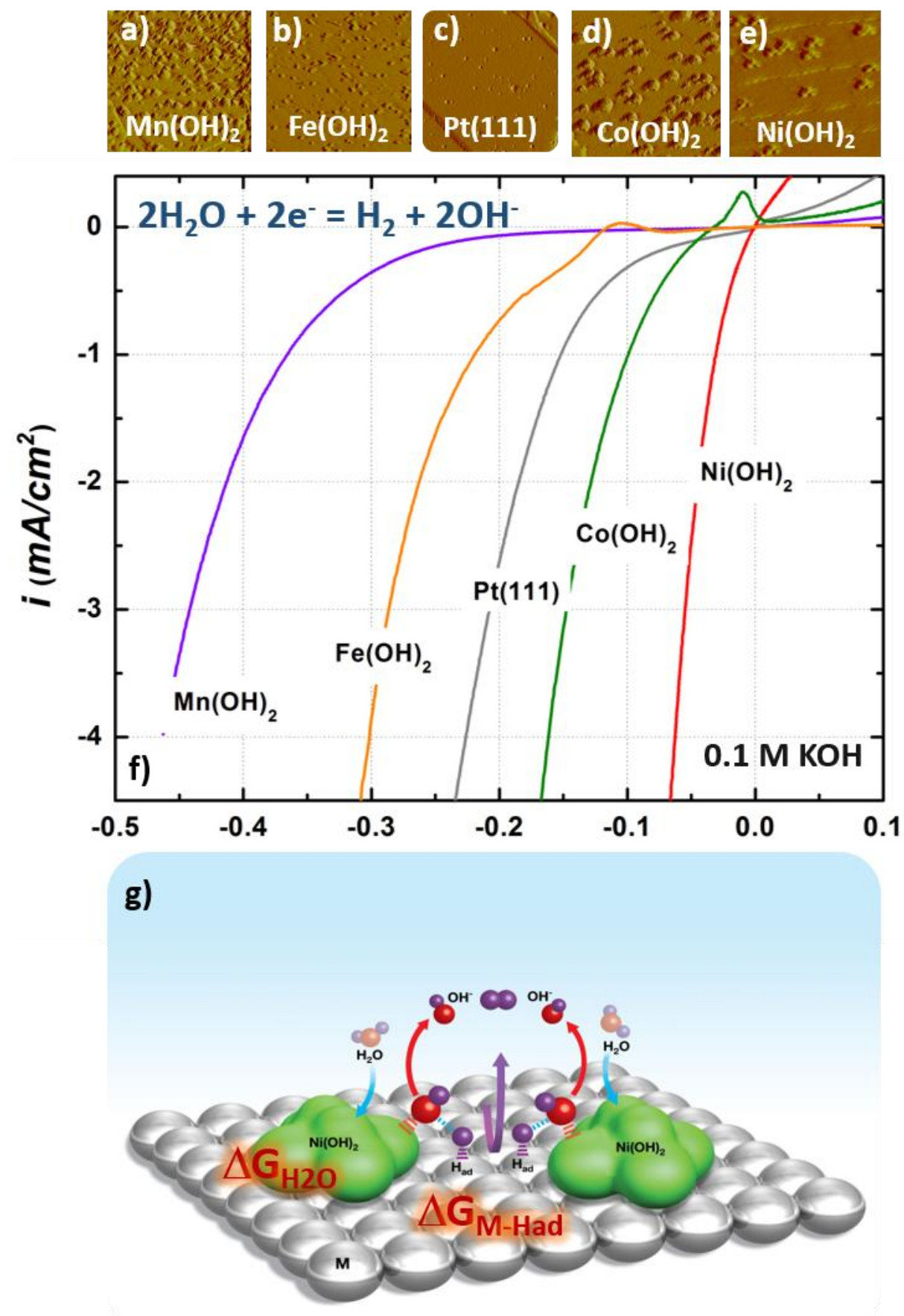

Figure 3: Effect of $\operatorname{Pt}(111)$ surface modification by transition metal hydroxides in alkaline solutions. STM images for the hydroxide modified surfaced (a-e) show fairly large (7-10 nm) clusters are randomly distributed on the $\mathrm{Pt}$ (111) terraces. HER polarization curves in $0.1 \mathrm{M} \mathrm{KOH}$ for $\operatorname{Pt}(111)$ surface modified with different transition metal hydroxides, with Pt-Ni(OH) $)_{2}$ as the most active and $\mathrm{Pt}-\left(\mathrm{Mn}(\mathrm{OH})_{2}\right.$ as the least active catalyst (f). Schematic representation of water dissociation on $\mathrm{Ni}(\mathrm{OH})_{2}$ clusters forming two 
$\mathrm{H}_{\mathrm{ad}}$ that recombine to form $\mathrm{H}_{2}$ on Pt surface in shown in (g). All STM images depict a 100x100 nm area. Polarization curves were measured at $50 \mathrm{mV} / \mathrm{s}, 1600 \mathrm{rpm}$. 


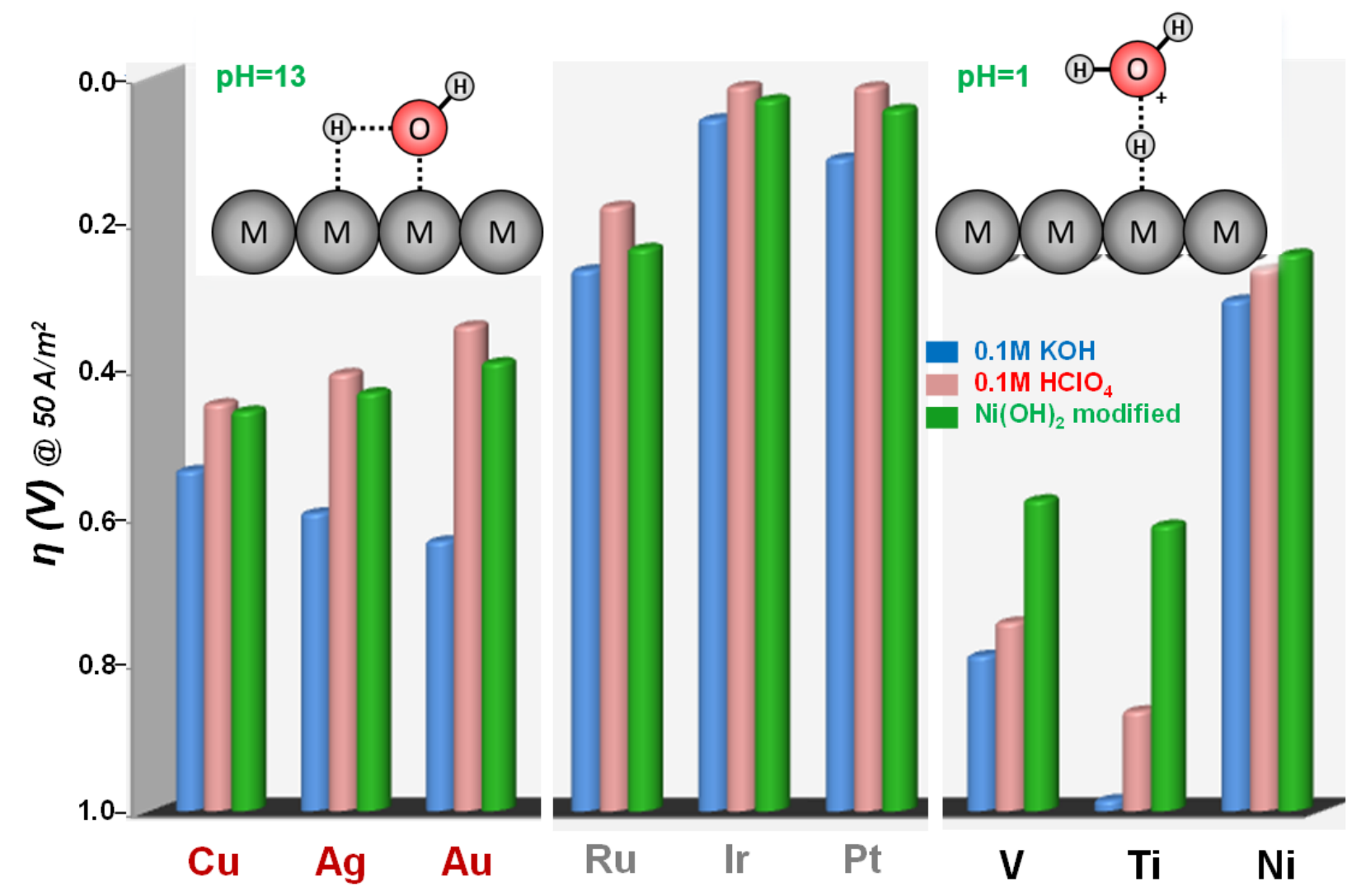

Figure 4: A bar graph of activities for HER represented as overpotential to achieve constant current of $50 \mathrm{~A} / \mathrm{m}^{2}$ in acid (red bars) and alkaline (blue bars) electrolyte for Pt-group metals, $1 \mathrm{~B}$ group metals and $3 \mathrm{~d}$ transition metals. The green bars represent activities for $\mathrm{Ni}(\mathrm{OH})_{2}$ modified surfaces in $0.1 \mathrm{M} \mathrm{KOH}$. The insets are schematic representations of activated complex at $\mathrm{pH} 13$ and $\mathrm{pH} 1$. Note that instead of a metal atom, an $\mathrm{OH}$ group of a metal hydroxide or some other entity can be a part of the activated complex. 


\section{References}

[1] P. Delahay, J. Am. Chem. Soc. 74 (1952) 3497-3500.

[2] P. Rüetschi, P. Delahay, J. Chem. Phys. 23 (1955) 195-199.

[3] S. Trasatti, J. Electroanal. Chem. Interfacial Electrochem. 39 (1972) 163-184.

[4] A.J. Appleby, Nature 253 (1975) 257-258.

[5] P.C.K. Vesborg, B. Seger, I. Chorkendorff, J. Phys. Chem. Lett. 6 (2015) 951-957.

[6] N.M. Markovic, Nat. Mater. 12 (2013) 101-102.

[7] J. Greeley, N.M. Markovic, Energy Environ. Sci. 5 (2012) 9246-9256.

[8] J. Herranz, J. Durst, E. Fabbri, A. Patru, X. Cheng, A.A. Permyakova, T.J. Schmidt, Nano Energy (2016) in press.

[9] T. Masuda, K. Shimazu, K. Uosaki, J. Phys. Chem. C 112 (2008) 10923-10930.

[10] L. Birry, A. Lasia, J. Appl. Electrochem. 34 (2004) 735-749.

[11] M.E. Bjorketun, A.S. Bondarenko, B.L. Abrams, I. Chorkendorff, J. Rossmeisl, Phys. Chem. Chem. Phys. 12 (2010) 10536-10541.

[12] B. Cao, G.M. Veith, J.C. Neuefeind, R.R. Adzic, P.G. Khalifah, J. Am. Chem. Soc. 135 (2013) 1918619192.

[13] W.F. Chen, C.-H. Wang, K. Sasaki, N. Marinkovic, W. Xu, J.T. Muckerman, Y. Zhu, R.R. Adzic, Energy Environ. Sci. 6 (2013) 943-951.

[14] B.E. Conway, Int. J. Hydrog. Energy 15 (1990) 701-713.

[15] M.J. De Giz, G. Tremiliosi-Filho, E.R. Gonzalez, S. Srinivasan, A.J. Appleby, Int. J. Hydrogen Energy 20 (1995) 423-427.

[16] J. Durst, C. Simon, F. Hasche, H. a. Gasteiger, J. Electrochem. Soc. 162 (2014) F190-F203.

[17] K. Elbert, J. Hu, Z. Ma, Y. Zhang, G. Chen, W. An, P. Liu, H.S. Isaacs, R.R. Adzic, J.X. Wang, ACS Catal. 5 (2015) 6764-6772.

[18] A. Han, S. Jin, H. Chen, H. Ji, Z. Sun, P. Du, J. Mater. Chem. A 3 (2015) 1941-1946.

[19] T.F. Jaramillo, K.P. Jørgensen, J. Bonde, J.H. Nielsen, S. Horch, I. Chorkendorff, Science 317 (2007) 100-102.

[20] J. Kibsgaard, T.F. Jaramillo, Angew. Chem. Int. Ed. Engl. 53 (2014) 14433-7.

[21] J. Kibsgaard, T.F. Jaramillo, F. Besenbacher, Nat. Chem. 6 (2014) 248-253.

[22] J. Kibsgaard, C. Tsai, K. Chan, J.D. Benck, J.K. Nørskov, F. Abild-Pedersen, T.F. Jaramillo, Energy Environ. Sci. 8 (2015) 3022-3029. 
[23] K.A. Kuttiyiel, K. Sasaki, W.-F. Chen, D. Su, R.R. Adzic, J. Mater. Chem. A 2 (2014) 591.

[24] A.B. Laursen, S. Kegnæs, S. Dahl, I. Chorkendorff, Energy Environ. Sci. 5 (2012) 5577.

[25] J. Li, Y. Wang, T. Zhou, H. Zhang, X. Sun, J. Tang, L. Zhang, A.M. Al-Enizi, Z. Yang, G. Zheng, J. Am. Chem. Soc. 137 (2015) 14305-14312.

[26] P. Los, A. Rami, A. Lasia, J. Appl. Electrochem. 23 (1993) 135-140.

[27] Q. Lu, G.S. Hutchings, W. Yu, Y. Zhou, R. V Forest, R. Tao, J. Rosen, B.T. Yonemoto, Z. Cao, H. Zheng, J.Q. Xiao, F. Jiao, J.G. Chen, Nat Commun 6 (2015) 6567.

[28] C.C.L. McCrory, S. Jung, I.M. Ferrer, S. Chatman, J.C. Peters, T.F. Jaramillo, J. Am. Chem. Soc. 137 (2015) 4347-4357.

[29] R. Michalsky, Y.-J. Zhang, A.A. Peterson, ACS Catal. 4 (2014) 1274-1278.

[30] D. Miousse, A. Lasia, J. New Mater. Electrochem. Syst. 2 (1999) 71-78.

[31] A. Morozan, V. Goellner, Y. Nedellec, J. Hannauer, F. Jaouen, J. Electrochem. Soc. 162 (2015) H719-H726.

[32] G. Soldano, E.N. Schulz, D.R. Salinas, E. Santos, W. Schmickler, Phys. Chem. Chem. Phys. 13 (2011) 16437-16443.

[33] J. Staszak-Jirkovský, C.D.D. Malliakas, P.P.P. Lopes, N. Danilovic, S.S.S. Kota, K.-C. Chang, B. Genorio, D. Strmcnik, V.R.R. Stamenkovic, M.G. Kanatzidis, N.M. Markovic, Nat. Mater. 15 (2015) 197-204.

[34] I.E.L. Stephens, I. Chorkendorff, Angew. Chemie Int. Ed. 50 (2011) 1476-1477.

[35] T.L. Tan, L.-L. Wang, J. Zhang, D.D. Johnson, K. Bai, ACS Catal. 5 (2015) 2376-2383.

[36] M. Xiao, R. Cheng, M. Hao, M. Zhou, Y. Miao, ACS Appl. Mater. Interfaces 7 (2015) 26101-26107.

[37] Z. Xing, Q. Liu, A.M. Asiri, X. Sun, ACS Catal. 5 (2015) 145-149.

[38] Y. Yang, H. Fei, G. Ruan, J.M. Tour, Adv. Mater. 27 (2015) 3175-3180.

[39] D. Ha, B. Han, M. Risch, L. Giordano, K.P.C. Yao, P. Karayaylali, Y. Shao-Horn Nano Energy (2016) in this "Electrocatalysis Special Issue."

[40] B.E. Conway, G. Jerkiewicz, Electrochim. Acta 45 (2000) 4075-4083.

[41] B.E. Conway, G. Jerkiewicz, Solid State Ionics 150 (2002) 93-103.

[42] B.E. Conway, B. V. Tilak, Electrochim. Acta 47 (2002) 3571-3594.

[43] M.M. Jaksic, Int. J. Hydrogen Energy 12 (1987) 727-752.

[44] J. Greeley, T.F. Jaramillo, J. Bonde, I.B. Chorkendorff, J.K. Nørskov, J.K. Norskov, Nat. Mater. 5 (2006) 909-913. 
[45] R. Subbaraman, D. Tripkovic, D. Strmcnik, K.-C.C. Chang, M. Uchimura, A.P. Paulikas, V. Stamenkovic, N.M. Markovic, Science 334 (2011) 1256-1260.

[46] J. Durst, A. Siebel, C. Simon, F. Hasche, J. Herranz, H.A. Gasteiger, Energy Environ. Sci. 7 (2014) 2255-2260.

[47] D.S. Strmcnik, D. V Tripkovic, D. van der Vliet, K.-C. Chang, V. Komanicky, H. You, G. Karapetrov, J.P. Greeley, V.R. Stamenkovic, N.M. Marković, J. Am. Chem. Soc. 130 (2008) 15332-15339.

[48] D. Strmcnik, M. Uchimura, C. Wang, R. Subbaraman, N. Danilovic, D. van der Vliet, A.P. Paulikas, V.R. Stamenkovic, N.M. Markovic, Nat. Chem. 5 (2013) 300-306.

[49] D. Eberhardt, E. Santos, W. Schmickler, J. Electroanal. Chem. 461 (1999) 76-79.

[50] E. Santos, a. Lundin, K. Pötting, P. Quaino, W. Schmickler, Phys. Rev. B - Condens. Matter Mater. Phys. 79 (2009) 1-10.

[51] E. Santos, K. Pötting, A. Lundin, P. Quaino, W. Schmickler, Chemphyschem 11 (2010) 1491-5.

[52] P. Quaino, F. Juarez, E. Santos, W. Schmickler, Beilstein J. Nanotechnol. 5 (2014) 846-854.

[53] J.K. Norskov, T. Bligaard, J. Rossmeisl, C.H. Christensen, Nat. Chem. 1 (2009) 37-46.

[54] M.T.M. Koper, Top. Catal. 58 (2015) 1153-1158.

[55] M.J. Kolb, F. Calle-Vallejo, L.B.F. Juurlink, M.T.M. Koper, J. Chem. Phys. 140 (2014) 134708.

[56] T. Bligaard, J.K. Nørskov, S. Dahl, J. Matthiesen, C.H. Christensen, J. Sehested, J. Catal. 224 (2004) 206-217.

[57] O.A. Petrii, G.A. Tsirlina, Electrochim. Acta 39 (1994) 1739-1747.

[58] T. Shinagawa, A.T. Garcia-Esparza, K. Takanabe, ChemElectroChem 1 (2014) 1497-1507.

[59] M. Auinger, I. Katsounaros, J.C. Meier, S.O. Klemm, P.U. Biedermann, A. a Topalov, M. Rohwerder, K.J.J. Mayrhofer, Phys. Chem. Chem. Phys. 13 (2011) 16384-16394.

[60] D.C. Barker, G.C.; Sammon, Nature 215 (1967) 324-325.

[61] W. Albery, Trans. Faraday Soc. (1966) 1575-1582.

[62] F.H. Stillinger, in:, H.E.D. Henderson (Ed.), Theor. Chem. Adv., Academic Press, New Yourk, 1978, pp. 177-234.

[63] J. Rossmeisl, K. Chan, E. Skúlason, M.E. Björketun, V. Tripkovic, Catal. Today 262 (2016) 36-40.

[64] N.M. Marković, B.N. Grgur, P.N. Ross, J. Phys. Chem. B 101 (1997) 5405-5413.

[65] N.M. Marković, P.N. Ross Jr., Surf. Sci. Rep. 45 (2002) 117-229.

[66] N.M. Markovic, S.T. Sarraf, H.A. Gasteigert, P.N. Ross, J. Chem. Soc., Faraday Trans. 92 (1996) 3719-3725. 
[67] M.J.T.C. van der Niet, A. den Dunnen, L.B.F.B.F. Juurlink, M.T.M.T.M. Koper, Angew. Chemie Int. Ed. 49 (2010) 6572-6575.

[68] F.T. Wagner, T.E. Moylan, Surf. Sci. 182 (1987) 125-149.

[69] P. Baumann, G. Pirug, D. Reuter, H.P. Bonzel, Surf. Sci. 335 (1995) 186-196.

[70] S.C. Chang, M.J. Weaver, J. Phys. Chem. 95 (1991) 5391-5400.

[71] M.A. Henderson, Surf. Sci. Rep. 46 (2002) 1-308.

[72] H. Li, Y. Li, M.T.M. Koper, F. Calle-Vallejo, J. Am. Chem. Soc. 136 (2014) 15694-15701.

[73] M.J.T.C. van der Niet, N. Garcia-Araez, J. Hernández, J.M. Feliu, M.T.M. Koper, Catal. Today 202 (2013) 105-113.

[74] M.T.M. Koper, Nanoscale 3 (2011) 2054-2073.

[75] F. Calle-Vallejo, D. Loffreda, K.T. M., P. Sautet, Nat Chem 7 (2015) 403-410.

[76] R. Subbaraman, D. Tripkovic, K.-C. Chang, D. Strmcnik, A.P. Paulikas, P. Hirunsit, M. Chan, J. Greeley, V. Stamenkovic, N.M. Markovic, Nat. Mater. 11 (2012) 550-7.

[77] P. Delahay, Double Layer and Electrode Kinetics, Interscience Publishers, 1965.

[78] M.R. Tarasevich, O. V. Korchagin, Russ. J. Electrochem. 49 (2013) 600-618.

[79] D. Strmcnik, K. Kodama, D. van der Vliet, J. Greeley, V.R. Stamenkovic, N.M. Markovic, Nat. Chem. 1 (2009) 466-472.

[80] E.G. Ciapina, P.P. Lopes, R. Subbaraman, E.A. Ticianelli, V. Stamenkovic, D. Strmcnik, N.M. Markovic, Electrochem. Commun. 60 (2015) 30-33.

[81] V.R. Stamenkovic, B.S. Mun, M. Arenz, K.J.J. Mayrhofer, C.A. Lucas, G. Wang, P.N. Ross, N.M. Markovic, Nat. Mater. 6 (2007) 241-247.

[82] M. Arenz, V. Stamenkovic, P.N. Ross, N.M. Markovic, Surf. Sci. 573 (2004) 57-66.

[83] N.M. Marković, T.J. Schmidt, V. Stamenković, P.N. Ross, Fuel Cells 1 (2001) 105-116.

[84] V.R. Stamenkovic, B. Fowler, B.S. Mun, G. Wang, P.N. Ross, C.A. Lucas, N.M. Marković, Science 315 (2007) 493-7.

[85] N. Danilovic, R. Subbaraman, D. Strmcnik, K.-C. Chang, A.P. Paulikas, V.R. Stamenkovic, N.M. Markovic, Angew. Chemie Int. Ed. 51 (2012) 12495-12498. 

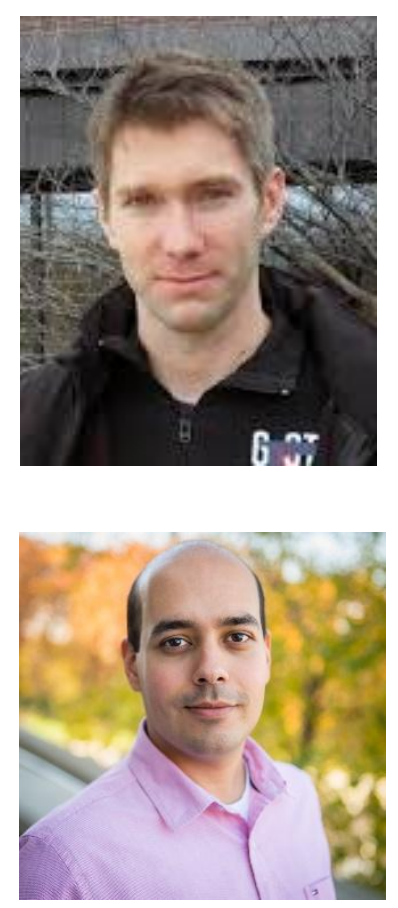

Pietro Papa Lopes obtained his Ph.D. in Chemistry at the Sao Carlos Chemistry Institute - University of Sao Paulo in 2013. He started his Post-Doctoral appointment at Argonne National Laboratory later that year, working on the development of new in situ (electro)analytical methods for simultaneous understanding of trends in activity-stabilityselectivity of materials employed in fuel cells and batteries in both aqueous and non-aqueous electrolytes.

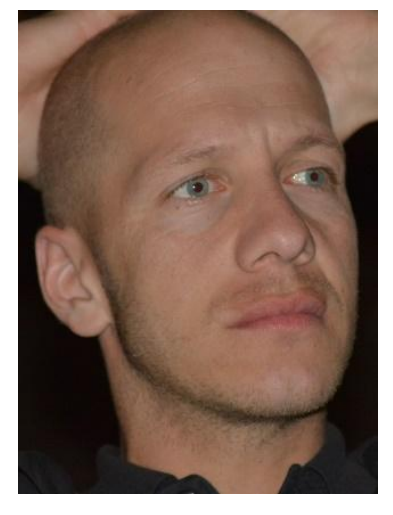

Prof. Dr. Bostjan Genorio is currently an assistant professor for Materials science at the Faculty of Chemistry and Chemical Technology, University of Ljubljana, Slovenia. He received his B. Sc. and Ph. D. degree from University of Ljubljana, Slovenia. Then he worked as a post-doctoral research associate with Prof. Dr. James M. Tour at Rice University, Houston, Texas, USA from 2011-2012. He was a visiting scientist at Materials Science Division, Argonne National Laboratory, Lemont, Illinois, USA from 2013-2015. His research interests are materials functionalization and design of selective solid-electrolyte interface for energy storage and conversion systems.

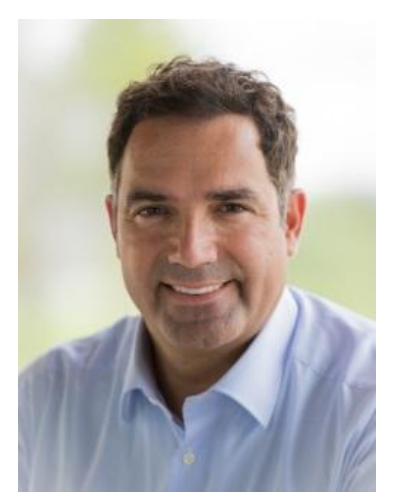

Vojislav R. Stamenkovic is a staff scientist and tech leader at Argonne National Laboratory. He received his Ph.D. degree in physical chemistry from University of Belgrade in 2001, after spending three years as a visiting scientist at the University of California at Berkeley. From 2002 to 2006 he was a postdoctoral and staff researcher within the Materials Sciences Division at the Lawrence Berkeley National Laboratory. In 2006, he has been appointed as a staff scientist in the Materials Science Division of Argonne National Laboratory. His research interests include materials for energy conversion and storage, electrocatalysis, 
spectroelectrochemistry and functional bio materials.

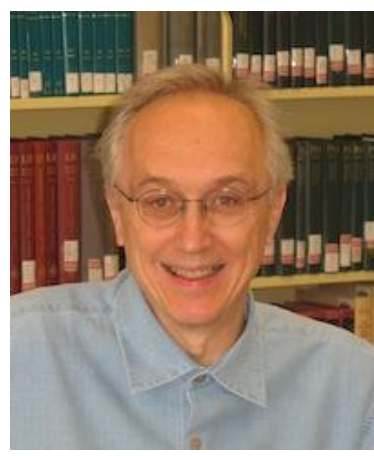

Nenad M. Markovic is an Argonne Distinguished Fellow and group leader at Materials Science Division. He received Ph.D. degree in Chemical Engineering at University of Belgrade in 1978. He was a postdoctoral researcher at the Case Western Reserve University and then he was a group leader at the Institute for Electrochemistry at University of Belgrade. From 1991 to 2005, he was a staff scientist at Lawrence Berkeley National Laboratory and then he joined Argonne National Laboratory in 2005 where he has been pursuing the research aimed to fundamental understanding of the electrified solid-liquid interfaces. The knowledge obtained by studying model systems he has been applying to energy conversion and storage systems. 
Descriptors for hydrogen evolution for water as proton donor:

- $\Delta \mathrm{G}$ for $\mathrm{H}_{2} \mathrm{O}$ dissociation on $\mathrm{M}(\mathrm{OH})_{2}$;

- $\Delta \mathrm{G}$ for $\mathrm{H}_{\mathrm{ad}}$ adsorption/recombination on Pt;

- $\Delta \mathrm{G}$ for $\mathrm{M}^{\mathrm{n}+} \ldots(\mathrm{OH})$ interaction.

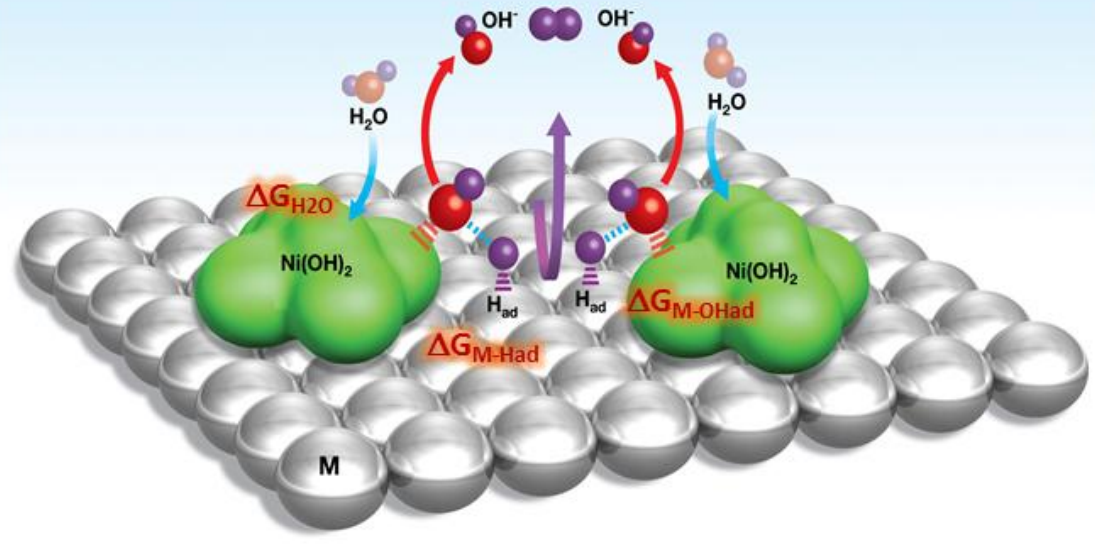

